International science (2): OAS

\section{Science for progress}

\author{
Mahindra Naraine traces the history of \\ the OAS's involvement in science in Latin America
}

$T_{\text {States (OAS) is probably the least }}^{\text {HE Organisation of American }}$ well known of the major international organisations. United States hegemony over the nations in the western hemisphere has resulted in scant attention being paid by 'outsiders' to the OAS and its operations. Yet it is interesting that the OAS is the oldest international organisation of its kind in the world. Not only that; for the past ten years it has also had a Scientific and Technological Programme. With a budget in 1976 of about $\$ 10$ million (about $20 \%$ of the OAS budget), this programme supports such work as the development of solar refrigeration in Mexico, the study of fur seals in Uruguay, computer technology in Brazil and deforestation studies in Haiti. In comparison with this the science and technology efforts of some other organisations seem puny.

Although the OAS has been in existence for some time its main preoccupation has been the idea of hemispheric peace, naturally under the guiding hand of the United States. The Cuban revolution and the Kennedy Administration together helped to speed up efforts aimed at the economic sector. The much-acclaimed Alliance for Progress, set in motion in August 1961 at Punta del Este (Uruguay), had the intention of eradicating economic under-development in Latin America. By the late 1960s corruption and maladministration minimised the potential benefits of the influx of some $\$ 1,000$ million into the region. The programme did not work well, and by 1967 it was obvious that a political boost to the OAS was necessary.

The American Chiefs of State met that year and in the 'Declaration of Punta del Este' stated that their aim was the creation of a Latin American Common Market. This was to begin in 1970 and to be in operation no later than 1985; it was to be a convergence of the then existing Latin American Free Trade Association and of the Central American Common Market system. The declaration also expressed the intention of harnessing science and technology for the service of the Latin American peoples. To effect this it was decided to establish a Regional Scientific and Technological Programe (PRDYCT). It was also stated that because of the magnitude of the investments required for science and technology, it was necessary to have inter-American cooperation. In compliance with the Punta del Este Declaration, the Inter-American Cultural Council formally established PRDCYT in February 1968. In this Resolution of, Maracay it was stated that PRDCYT

shall be oriented towards the adoption of measures to promote scientific and technological research, teaching and information, basic and advance training of scientific and technical personnel, ánd exchange of information. It shall intensively promote the transfer to and adaptation by the Latin American countries of knowledge and technology originating in other parts of the world.

PRDCYT was not the first programme of a technical nature to exist in the OAS. As far back as 1950 a programme of Technical Cooperation was created to deal with requests for technical assistance. With the advent of the Alliance for Progress there was a rapid expansion of technical assistance projects. The OAS then established a special training programme in which, for the first time in OAS history, countries outside the hemisphere could participate. Several European countries participated, but the most significant contribution in this category has come from Israel. In 1975, for instance, Israel provided $70 \%$ of the experts for technical cooperation from non-member countries. Mechanisms for the operation of

A union of American Republics has existed since 1890 but it was only in 1948 that a Charter was drawn up and the Organisation of American States created. The OAS consists of 25 member countries spread over two continents and six islands in the Caribbean. Cuba still remains a member but in 1962 was excluded from participation in OAS affairs.

Early attempts were made by Simon Bolivar to develop the ideal of regional solidarity, but these failed. It was not untl the Monroe Doctrine and the idea of the Western Hemisphere as the region of United States influence that hemispheric unity, even if somewhat unbalanced, was feasible. The OAS has therefore suffered the criticism that most of its actions have been for the benefit of the dominant partner-the US.

OAS headquarters are in Washington; 18 of the member countries are Spanishspeaking. Other related OAS organisations include:

The Pan American Health Organisation (PAHO). Based in Washington, this was founded in 1902 and promotes and co-
PRDCYT were somewhat predetermined by the imperatives of integration and infrastructure. PRDCYT set out to create centres of excellence for the training of personnel from all the member countries. Three mechanisms were involved: multinational projects, supporting actions and basic studies.

Multinational projects are activities that are carried out in one or more centres in the region with the cooperation of several or all member states. Activities could be of a regional, subregional or national character. Regional activities are carried out in selected centres and in general consist of special courses, seminars and other types of technical meetings. Activities within the national sphere are meant for institutional development and to improve research and education. The OAS identified two kinds of centres: a responsible centre operated as headquarters for regional activities and provided assistance at a national level to less well endowed centres; centres that received these benefits were called participating centres.

For the less well endowed centres 'supporting actions' were expected to strengthen the scientific and technological infrastructure by building up equipment and other resources. The third mechanism, basic studies, was meant to obtain information on the region's scientific and technological capability and development.

\section{Main emphasis}

In the early years of PRDCYT the main emphasis was on multinational projects. These were allocated about $60 \%$ of the budget, in keeping with the big push for Latin American integration. There were multinational projects on mathematics, physics,

ordinates hemispheric efforts to combat disease, lengthen life and promote health in general. PAHO also serves as a regional agency of WHO and maintains close relations with the national health services in member countries. In 1974 75 its budget was $\$ 34$ million.

The Inter-American Institute of Agricultural Sciences (IICA). Founded in 1942 with headquarters in Costa Rica, it is the specialised unit of the OAS for agriculture and does teaching, research, technical assistance and conservation. Its activities are spread over the four geographic zones of the region. IICA manages the Simon Bolivar fund set up for rural development.

The Inter-American Nuclear Energy Commission (IANEC). This is a technical commission set up in 1959 to serve as a centre of information and consultation for the member states and to offer them the necessary cooperation and assistance for the peaceful uses of nuclear energy. The commission is financed mainly by funds from the regular budget of the OAS. 
chemistry, genetics, biochemistry and so on. Not all the countries benefited equally from the project, however. The more developed countries had had a greater exposure to science and made more use of the new opportunities.

The main criticism, however, came from Latin American academics, mainly social scientists. Continued pressure resulted in the OAS sponsored "Conference on the Application of Science and Technology to Latin American Development' (CACTAL). This conference was held in 1972 in Brazilia and its recommendations, called the Consensus of Brazilia, had a major impact.

Essentially CACTAL posited that development of a scientific and technological infrastructure that was not very closely linked to the productive sector was fruitless. What was important was that national science policies be closely coordinated with economic and social policies. There must be removal of technological dependence on the developed nations, indigenous technologies had to be developed, teaching and research should be geared to the labour market and the productive sector, scientific and technological development should give preference to the rural and urban marginal sectors and national science policies should look at such matters as patents, trademark legislation and technology transfer agreements.

The OAS noted the resolutions and attempted to modify its programme. The OAS 'Mar del Plata Resolution' acknowledged that the structure of PRDCYT was too rigid to meet the demands of the member states in a timely manner. It recommended that more attention be paid to economic and social development; for this there would be a revision of the fields of action and types of activities. It was agreed that there was an urgent need for scientific and technological development in the developing countries; for this a special Mar del Plata fund was created giving preference to them.

\section{Funding}

The nature of the funding of OAS activities is somewhat complex. There is an OAS general fund to which all members contribute according to quotas established by the OAS secretariat. The total budget for 1961 was $\$ 8.3$ million. In 1968 it was $\$ 17.2$ million and in $1975 \$ 56.5$ million.

PRDCYT is administered by the Permanent Executive Committee of the Inter-American Council for Education, Science and Culture (CEPCIECC). CEPCIECC works out a budget for its fiscal period in line with previous years and proposed projects. Members are then asked to pledge amounts to this CEPCIECC fund in a similar ratio to the OAS general fund. Contributions are voluntary. Typical ratios are $0.19 \%$ for the poorest countries, $7.4 \%$ for countries like Brazil and Argentina, and $66 \%$ for the United States.

The CEPCIECC budget is for science, education and culture. Until 1974 PRDCYT was allocated $60 \%$ of the budget but this figure has since been reduced to $50 \%$. It has been said that the change is a consequence of most of the representatives on CEPCIECC being Ministers of Education. In its first year of operation PRDCYT was allocated $\$ 2.4$ million excluding administration costs. In the first three years the programme disbursed some $\$ 18$ million. For the next five years over $\$ 50$ million was spent.

The funding has been further complicated by the creation of the Mar del Plata fund in 1974. Under this each country has a multiplier factor; the poorer the country, the higher the multiplier. Countries whose quota to the general OAS fund is less than $0.75 \%$ have a multiplier of about 7 ; for a country like Mexico it is 1.9. A country then allocates money to this special fund providing it does not exceed the sum it contributes to the regular fund. This contribution is then increased by the multiplier factor; the matching funds are made up mainly by the United States. For the 1974-76 period the Mar del Plata account had some $\$ 5.8$ million.

At the present time PRDCYT acts in areas of basic and applied sciences (supporting the funding of research projects and training of personnel), technological research and the transfer of technology. It is also involved in scientific and technological policy and planning-helping in the formulation of national science policies.

Applications for support are sent through the national science agencies to the OAS. The OAS has a panel of experts which provides technical guidance on the application. Projects can request training of personnel, recruitment of visiting professors, equipment, books and so on, but do not cover administration expenses or other requirements. In compliance with political attempts at integration, however, preference is given to projects that are multinational, so that proposals always include provision for contact or assistance with other regional institutions or personnel.

\section{Main problem}

Ironically, PRDCYT's main problem has been its association with the OAS. The programme was developed through political actions and it has never lost that association in the eyes of its critics. The United States' dominance

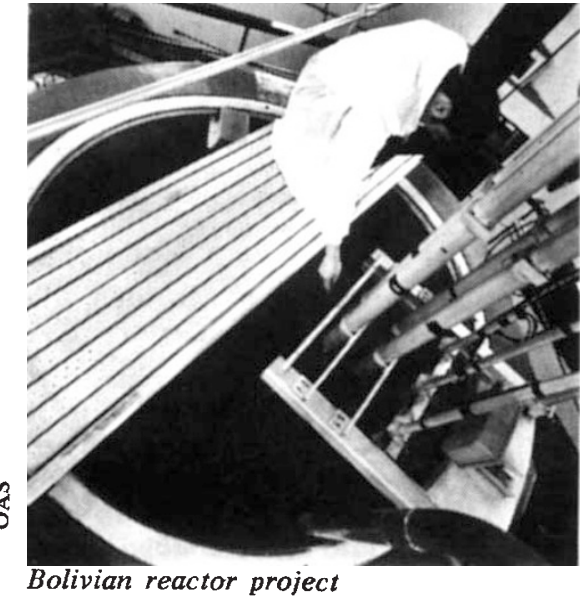

of the OAS and its manipulation of the region to secure hemispheric solidarity has raised many doubts about the worth of any OAS programme.

Undoubtedly, the benefits have not been as large as they might have been. The more developed countries have benefited most from the programme, but this should be expected since they have a better science and technology infrastructure. The Mar del Plata account has helped to redress the balance, but the main issue here is that it limits the amount of money countries can obtain. The newly created Simon Bolivar fund, financed mainly by Venezuelan petrodollars, will concentrate its efforts on rural development-PRDCYT's main problem is that it has not been closely linked to direct economic development. Criticisms of it on technology transfer conditions, patent legislation and types of development, however, are spurious, since these are issues that have to be settled internally by national policies. Awareness of these problems on the part of some national agencies has actually stemmed partly from PRDYCT-organised courses, but these agencies find it difficult to convince their superiors of the need for integrated science policies.

PRDCYT has been important in the development of the scientific and technological infrastructure of the Latin American nations. Through its efforts many centres of excellence now exist that are the prerequisites for the generation of indigenous technology. Many institutions rely on the programme for financial support for research, since they receive very little money directly from their own governments. According to Article 45 of the OAS Charter, governments should encourage science that is oriented toward the overall improvement of the individual-that is a foundation for democracy, social justice and progress. In too many Latin American countries money is used for the very opposite purposes. 